\title{
탈

\section{Transparência e Acesso à Informação na Atuação Internacional do Município de São Paulo}

\author{
Transparencia y Acceso a la Información en la Acción Internacional del \\ Municipio De São Paulo
}

Transparency and Access to Information in the International Performance of the Municipality of São Paulo

\author{
Danilo Garnica Simini ${ }^{1}$ (id \\ José Blanes Sala²
}

DOI: $10.22478 / u f p b .2525-5584.2020 v 5 n 2.52187$

Recebido em:29/04/2020

Aprovado em: 03/08/2020

\begin{abstract}
Resumo: A Constituição Federal, inserida em um contexto de descentralização política, conferiu aos municípios um papel de destaque na organização do Estado brasileiro, conferindo-lhes autonomia, além de competências próprias. A descentralização e a valorização do poder local teve como objetivos maximizar o ideal democrático, a fim de facilitar a participação da população nas políticas públicas, possibilitando também sua fiscalização. Contudo, os municípios acabaram sendo colocados diante de um novo desafio, pois a sua valorização acabou sobrecarregando os poderes locais em razão das novas atribuições. No sentido de superar o desafio proposto fez com que os municípios buscassem novas alternativas em termos de políticas públicas, surgindo, dentre as novas formas, a atuação internacional como política pública. O município de São Paulo é considerado um dos pioneiros em termos de atuação internacional em razão da criação de uma Secretaria Municipal de Relações Internacionais, hoje transformada em Coordenadoria de Relações Internacionais vinculada ao Gabinete do Prefeito. O presente trabalho, ao estabelecer ser a atuação internacional de municípios uma forma de política pública, busca investigar se há demanda por parte da sociedade em relação à transparência e o acesso à informação na atuação internacional do município de São Paulo. O artigo analisa os pedidos de acesso à informação feitos nos últimos em São Paulo a fim de tentar mensurar a participação da sociedade na atuação internacional da capital paulista.
\end{abstract}

\footnotetext{
1 Universidade de Ribeirão Preto (UNAERP); Universidade Federal do ABC (UFABC). E-mail: danilosimini@gmail.com.

${ }^{2}$ Universidade Federal do ABC (UFABC). E-mail: blanes@ufabc.edu.br.
} 

de São Paulo

Palavras-chave: Transparência; Acesso à Informação; Atuação Internacional de Municípios; São Paulo; Secretaria Municipal de Relações Internacionais.

Resumen: La Constitución Federal, insertada en un contexto de descentralización política, otorgó a los municipios un papel destacado en la organización del Estado brasileño, concediéndoles autonomía, además de sus propias competencias. La descentralización y la valorización del poder local apuntan a maximizar el ideal democrático, a fin de facilitar la participación de la población en las políticas públicas, al tiempo que permite su inspección. Sin embargo, los municipios terminaron enfrentando un nuevo desafío, ya que su valorización terminó sobrecargando a los poderes locales debido a las nuevas atribuciones. Para superar el desafío propuesto, los municipios buscaron nuevas alternativas en términos de políticas públicas, con acciones internacionales como políticas públicas que emergen de las nuevas formas. El municipio de São Paulo es considerado uno de los pioneros en términos de actividad internacional debido a la creación de una Secretaría Municipal de Relaciones Internacionales, que hoy se transformó en la Coordinación de Relaciones Internacionales vinculada a la Alcaldía. El presente trabajo, al establecer que el desempeño internacional de los municipios es una forma de política pública, busca investigar si existe una demanda de la sociedad en relación con la transparencia y el acceso a la información en el desempeño internacional del municipio de São Paulo. El artículo analiza las solicitudes de acceso a la información realizadas en los últimos años en São Paulo para tratar de medir la participación de la sociedad en el desempeño internacional de la capital del estado de São Paulo.

Palabras clave: transparencia; acceso a la información; desempeño internacional de municipios; São Paulo; Secretaría Municipal de Relaciones Internacionales.

Abstract: The Federal Constitution, inserted in a context of political decentralization, gave the municipalities a prominent role in the organization of the Brazilian State, giving them autonomy, in addition to their own competences. Decentralization and the valorization of local power aimed at maximizing the democratic ideal, in order to facilitate the participation of the population in public policies, while also enabling their inspection. However, the municipalities ended up being faced with a new challenge, as their valorization ended up overloading the local powers due to the new attributions. In order to overcome the proposed challenge, municipalities sought new alternatives in terms of public policies, with international actions as public policies emerging from the new forms. The municipality of São Paulo is considered one of the pioneers in terms of international activity due to the creation of a Municipal Secretariat for International Relations, which today is transformed into the International Relations Coordination linked to the Mayor's Office. The present work, by establishing that the international performance of municipalities is a form of public policy, seeks to investigate whether there is a demand from society in relation to transparency and access to information in the international performance of the municipality of São Paulo. The article analyzes the requests for access to information made in the last ones in São Paulo in order to try to measure the participation of society in the international performance of the capital of São Paulo.

Keywords: Technological Innovation; Political Economy; China; Development. 
Simini \& Sala. Transparência e Acesso à Informação na Atuação Internacional do Município de São Paulo

\section{Introdução}

Os anos 1990 foram o cenário temporal para o surgimento de uma nova prática em termos de políticas pública no Brasil. O contexto da Constituição Federal de 1988 estimulou os municípios brasileiros a adotarem outras práticas em razão de suas novas responsabilidades públicas. Assim, surge a atuação internacional de municípios no Brasil como forma dos municípios suprirem suas demandas introduzidas pelas novas circunstâncias políticas e jurídicas.

A atuação internacional de municípios constitui uma realidade no Brasil, mesmo sendo ainda restrita aos municípios de grande e médio porte. Trata-se de um campo de estudos nas Relações Internacionais, na Ciência Política e no Direito. Contudo, conforme observam Leonardo Mercher e Alexsandro Eugênio Pereira (2018), os estudos realizados, ao menos de forma majoritária, acabam apenas descrevendo a atuação internacional de determinados municípios no Brasil.

Os trabalhos sobre atuação internacional de municípios no Brasil como política pública e seus desdobramentos são poucos. Além do debate acerca desta prática municipal como exemplo de política pública, outras discussões também devem ser realizadas, tais como a participação da sociedade civil, a existência ou não de transparência administrativa na atuação internacional de municípios e até mesmo a fiscalização desta prática tão importante para muitas cidades.

O presente artigo visa contribuir com os estudos sobre atuação internacional de municípios no Brasil na perspectiva da prática como política pública. A atuação internacional do poder local no Brasil ao ser entendida como política pública exige questionamentos a respeito de sua democratização e esta somente se concretiza com transparência administrativa e acesso à informação por parte da sociedade civil. A participação nas políticas públicas somente será possível e eficaz na medida em que a população tenha ciência da forma mais ampla possível da própria atuação pública em suas múltiplas facetas, dentre elas a atuação internacional dos municípios.

Portanto, busca-se no artigo investigar se há demanda por parte da sociedade civil no que diz respeito à transparência e acesso à informação na atuação internacional de municípios no Brasil. O município de São Paulo, em razão do seu pioneirismo e do seu destaque, foi o escolhido como objeto de análise. Através do levantamento dos relatórios anuais sobre acesso à informação, divulgados pela própria municipalidade, busca-se 
Simini \& Sala. Transparência e Acesso à Informação na Atuação Internacional do Município de São Paulo

analisar se há transparência administrativa e demanda por acesso à informação na capital paulista no que se refere à atuação internacional. Assim, espera-se, ao menos de forma preliminar, tecer considerações acerca de uma possível democratização e também fiscalização da atuação internacional de municípios.

\section{A Atuação Internacional de Municípios no Brasil como Política Pública}

Marcus André Melo (1999) explica que a América Latina a partir da década de 1980 se transformou em um verdadeiro laboratório de experiências reformistas relacionadas à agenda neoliberal. A descentralização esteve na pauta destas reformas neoliberais e instituições de alcance global como o Banco Mundial, o Fundo Monetário Internacional e o Banco Interamericano de Desenvolvimento; todos eles tiveram papel importante na difusão da ideia de descentralização. O autor explica que a descentralização deve ser entendida como transferência de poder decisório para os entes locais e também como adoção de medidas democratizantes, participativas e de responsabilização.

A partir destas circunstâncias deve ser interpretada a Constituição Federal de 1988 e a organização do Estado brasileiro dela decorrente, ou seja, devem ser analisadas no contexto das reformas neoliberais introdutórias de uma nova visão de Estado com a valorização do poder local, seja por questões de eficiência da máquina pública ou por questões relacionadas ao controle social do poder político e sua democratização. Pode-se dizer, desta forma, que a descentralização se constitui numa tentativa de aproximar o poder político da população, facilitando a sua participação e o controle da atividade pública.

A Constituição Federal de 1988 consagra no Brasil a adoção do federalismo e, consequentemente, a união indissolúvel dos entes federativos, quais sejam, a União, os Estados-membros, Distrito Federal e Municípios, garantindo a cada ente federativo autonomia financeira, política e administrativa. Ademais, deve-se ressaltar ser o federalismo brasileiro classificado como cooperativo, pois cada ente possui suas próprias competências e ao mesmo tempo a Constituição Federal (artigo 23) estabelece matérias de competência comum de todos os entes da federação, tais como saúde, assistência social, preservação do meio ambiente, combate à pobreza, cultura, etc. A literatura (SOUZA, 2005) explica que os constituintes ao estabelecerem o artigo 23 no texto constitucional indicaram ser de responsabilidade comum de todos os entes federativos o oferecimento dos principais serviços públicos.

Revista Brasileira de Políticas Públicas e Internacionais, v. 5, n. 2, ago./2020, pp. 79-102. 
Simini \& Sala. Transparência e Acesso à Informação na Atuação Internacional do Município de São Paulo

No contexto do federalismo brasileiro, deve-se destacar a figura do município enquanto parte integrante do Estado brasileiro e reconhecido como ente federativo, sendo o Brasil o primeiro país a fazer tal reconhecimento (BLANES SALA e CARVALHO, 2013). O reconhecimento do município como ente federativo lhe conferiu autonomia e competências próprias, tornando-o um importante agente em termos de políticas públicas (MOHN, 2006).

O artigo 30 da Constituição Federal de 1988 confere aos municípios competência para tratar de assuntos de interesse local. A expressão interesse local não é de fácil interpretação e não pode ser entendida como sinônimo de interesse exclusivo. O texto constitucional ao estabelecer a repartição de competências utilizou como critério o princípio da predominância do interesse. Assim, se o município, por exemplo, tiver um interesse predominante em determinada matéria esta será de sua competência e atribuição. Nessas circunstâncias, o município, ao ser valorizado pela Constituição Federal de 1988, acaba também ficando sobrecarregado em termos de atribuições e responsabilidades, pois diversas matérias acabam sendo de interesse municipal.

O novo perfil político-jurídico dos municípios brasileiros - valorizado e sobrecarregado - acabou estimulando novas alternativas em termos de formulação e implementação de políticas públicas locais. Muitos municípios brasileiros (e também Estados-membros) passaram a atuar de forma internacional, estabelecendo acordos de cooperação com outros entes locais estrangeiros e organismos internacionais como forma de suprir as novas demandas públicas introduzidas pelo texto constitucional. Portanto, pode-se dizer que o contexto da redemocratização e da descentralização no Brasil existente na Constituição Federal de 1988 favoreceu o início da atuação internacional dos entes subnacionais.

A atuação internacional de municípios no Brasil é uma ferramenta encontrada principalmente em cidades de grande e médio-porte (RIBEIRO, 2009; FONSECA, 2013; LAISNER, 2013; SIMINI, 2015; JUNQUEIRA, 2015), porém é inegável sua importância em termos de políticas públicas. A atuação internacional de municípios no Brasil ocorre em diversos temas, tais como educação, saúde, ciência, tecnologia, cultura, não havendo qualquer conflito entre os temas discutidos pelos municípios por meio de sua atuação internacional e aqueles relacionados ao governo federal (VIGEVANI, 2006).

Leonardo Mercher e Alexsandro Eugênio Pereira (2018) afirmam que é plenamente possível entender a atuação internacional de municípios como exemplo de

Revista Brasileira de Políticas Públicas e Internacionais, v. 5, n. 2, ago./2020, pp. 79-102. 
Simini \& Sala. Transparência e Acesso à Informação na Atuação Internacional do Município de São Paulo

política pública. A relação se mostra adequada, pois as políticas públicas constituem o "campo do conhecimento que busca, ao mesmo tempo, "colocar o governo em ação" e/ou analisar essa ação (variável independente) e, quando necessário, propor mudanças no rumo ou curso dessas ações (variável dependente)" (SOUZA, 2006, p. 26). Ou seja, se as políticas públicas analisam a ação dos governos, consequentemente a análise da atuação dos governos municipais por meio de articulações internacionais também deve ser entendida como política pública. Assim também ocorre com a política externa exercida pelo governo federal, igualmente entendida como política pública pela literatura (RATTON SÁNCHEZ et al., 2006).

A política pública exercida por meio da atuação internacional no Brasil pode ser institucionalizada através de Assessorias, Secretarias ou Coordenadorias (FONSECA, 2013). A atuação através das Secretarias Municipais constitui a forma mais sólida da atuação internacional de municípios e já foi objeto de estudos nos mais variados campos do conhecimento (BRIGAGÃO, 2005; RIBEIRO, 2009; CNM, 2011; FONSECA, 2013; LAISNER, 2013; JUNQUEIRA, 2015). Em razão da amplitude da atuação internacional dos municípios, o presente artigo irá tratar apenas da atuação internacional como política pública exercida através da Secretaria Municipal de Relações Internacionais de São Paulo.

\section{A Atuação Internacional do Município de São Paulo}

O município de São Paulo certamente pode ser considerado pioneiro e um dos mais atuantes em termos de atuação internacional de municípios, sendo objeto de diversas análises (FRONZAGLIA, 2005; SANTOS, 2010; ARAÚJO, 2012; SIMINI, 2015; VITAL, 2016; SIMINI e LAISNER, 2018). Inicialmente, deve-se lembrar da própria Lei Orgânica do Município de São Paulo, especificamente, seu artigo $4^{\circ}$, cuja redação enuncia que “[...] o Município, respeitados os princípios do art. $4^{\circ}$ da Constituição da República, manterá relações internacionais, através de convênios e outras formas de cooperação.” (SÃO PAULO, 1989, grifo nosso). A inserção deste dispositivo na Lei Orgânica de São Paulo foi feita através do então vereador Pedro Dallari, hoje docente do curso de Relações Internacionais da Universidade de São Paulo (IRI-USP). De acordo com José Blanes Sala e Clara Maria Faria Santos (2009, p. 143), “[...] não existe no Brasil dispositivo similar apto a garantir com a mesma eficácia jurídica a atuação internacional dos poderes municipais.”

A primeira experiência internacional em termos institucionais ocorreu na administração Luiza Erundina (PT) entre os anos de 1989 a 1992 com a criação da 
Simini \& Sala. Transparência e Acesso à Informação na Atuação Internacional do Município de São Paulo

Coordenadoria de Relações Internacionais vinculada à Secretaria de Negócios Extraordinários. Nas administrações seguintes, especificamente, nas de Paulo Maluf (PDS) e Celso Pitta (PPB) houve a extinção da citada Coordenadoria, o que fez com que cada Secretaria Municipal desenvolvesse por conta própria projetos na esfera internacional. Posteriormente, no ano de 2001, com o início da administração Marta Suplicy (PT) houve, por meio da Lei no 13.165/2001 (SÃO PAULO, 2001), a criação da Secretaria Municipal de Relações Internacionais (SMRI-SP), pasta com orçamento e estrutura próprios. Recentemente, com a edição do Decreto 58.954/2019, houve uma reorganização da administração pública municipal em São Paulo, sendo criada uma Coordenadoria de Relações Internacionais vinculada ao gabinete do Prefeito. Portanto, a pasta perde o status de Secretaria.

A atuação internacional de São Paulo se dá por meio de acordos de cooperação bilateral e multilateral, participação em redes de cidades e em eventos internacionais. Os acordos de cooperação bilateral são firmados “[...] quando há interesse de ambas as partes em estreitar laços políticos e culturais, a fim de viabilizar projetos e iniciativas em parceria.” (SÃO PAULO, [2020a], grifo nosso). O site (última atualização em 11/06/2019) da pasta indica como exemplos de acordos de cooperação bilateral: 1) Acordo de cooperação celebrado no ano de 2014 com a cidade argentina de Quilmes nas áreas de turismo, educação, esportes, ciência e tecnologia, comércio e indústria; 2) Acordo de cooperação celebrado no ano de 2018 com o Banco de Desenvolvimento da China referente ao intercâmbio e treinamento de pessoas; 3) Acordo de cooperação celebrado no ano de 2018 com a cidade italiana de Milão nas áreas de mobilidade urbana, gestão de resíduos, serviços ambientais, segurança e cultura; 4) Acordo de cooperação celebrado no ano de 2017 com a cidade italiana de Veneza na área de cultura; 5) Acordo de cooperação celebrado no ano de 2016 com a Cidade do México na área de saúde; 6) Acordo de cooperação celebrado no ano de 2019 com o Consulado Geral Britânico em São Paulo nas áreas de inovação, tecnologia, mobilidade urbana, transportes, infraestrutura, energia e saúde (SÃO PAULO, [2020a]).

Há também na categoria dos acordos de cooperação bilateral os chamados acordos bilaterais de Cidades-Irmãs, que “[...] podem propiciar troca de conhecimentos sobre políticas públicas e projetos em diversas áreas como programas de saúde, políticas culturais, e outros temas de interesse mútuo das cidades.” (SÃO PAULO, [2020a], grifo nosso). De acordo com o próprio órgão municipal da capital paulista, estes representam

Revista Brasileira de Políticas Públicas e Internacionais, v. 5, n. 2, ago./2020, pp. 79-102. 
Simini \& Sala. Transparência e Acesso à Informação na Atuação Internacional do Município de São Paulo

"o substrato formal e legal para o estabelecimento de eventuais acordos de cooperação técnica, programas de intercâmbio e desenvolvimento econômico, e atendimento à comunidade descendente do país ou região da cidade irmã." (SÃO PAULO, [2020a], grifo nosso). Os acordos bilaterais de Cidades-Irmãs estão consolidados juridicamente por meio da Lei Municipal no 14.471/2007 (SÃO PAULO, 2007), tendo o município de São Paulo atualmente trinta e uma cidades-irmãs (SÃO PAULO, [2020a]).

Os acordos de cooperação multilateral são instrumentos firmados no âmbito de organizações internacionais. De acordo com o site da pasta (última atualização em 05/07/2019) foram firmados nos últimos importantes acordos de cooperação multilateral, tais como: 1) Memorando de Entendimento entre a Organização dos Estados Iberoamericanos para a Educação, a Ciência e a Cultura e a Prefeitura de São Paulo, cujo objetivo é estabelecer mecanismos de cooperação entre as partes e estimular a atuação conjunta e colaborativa em áreas de interesse comum; 2) Memorando de Entendimento entre a Organização das Nações Unidas - ONU e a Prefeitura do Município de São Paulo, cujo objetivo é estabelecer mecanismos de cooperação entre as partes e estimular a atuação conjunta e colaborativa em áreas de interesse comum; 3) Termo de Cooperação Técnica entre o Município de São Paulo e o Fundo das Nações Unidas para a Infância UNICEF, cujo objetivo é a implementação da Plataforma dos Centros Urbanos para promover os direitos das crianças e dos adolescentes mais afetados pelas desigualdades nos centros urbanos do Brasil; 4) Protocolo de Intenções entre a Prefeitura do Munícipio de São Paulo e o Programa Mundial de Alimentos das Nações Unidas - PMA, cujo objetivo é o compartilhamento de experiências brasileiras de segurança alimentar e social, apoio e aprimoramento de projetos locais; 5) Memorando de Entendimento "Ligue os Pontos”, cujo objetivo é a implementação do Projeto Ligue os Pontos, iniciativa para desenvolver a produção de pequenos agricultores, ampliar suas fontes de renda, conectálos aos potenciais consumidores e preservar áreas de mananciais (SÃO PAULO, [2020b]).

Há ainda a participação internacional por meio das chamadas "redes de cidades". O site (última atualização em 01/02/2019) da pasta indica que o município de São Paulo participa das seguintes redes de cidades: 1) Grupo C40 de Grandes Cidades para a Liderança Climática - C40; 2) Cidades e Governos Locais Unidos - CGLU; 3) Mercocidades; 4) Associação Mundial das Grandes Metrópoles - Metropolis; 5) Open 
Simini \& Sala. Transparência e Acesso à Informação na Atuação Internacional do Município de São Paulo

Government Partnership; 6) Pacto de Milão; 7) União de Cidades Capitais Iberoamericanas - UCCI; 8) Urban 20 (SÃO PAULO, [2020c]).

A atuação internacional da capital paulista constitui, portanto, um instrumento importante em termos de políticas públicas municipais, pois apresenta orçamento próprio, funcionários, celebra contratos, bem como formula e implementa políticas através de acordos de cooperação internacional e por meio da participação em redes de cidades. Partindo-se da premissa de ser a atuação internacional do município de São Paulo uma política pública deve-se agora discutir a transparência e o acesso à informação desta atuação, pois conforme explicado anteriormente a descentralização das políticas públicas no Brasil teve por objetivos maximizar a participação da sociedade, inclusive em termos de fiscalização e controle. A participação e o controle, por sua vez, exigem transparência administrativa e o acesso à informação.

\section{O Acesso à Informação como Direito e a sua Regulamentação}

O acesso à informação constitui um direito previsto nos principais tratados de direitos humanos e também no ordenamento jurídico brasileiro. O artigo XIX da Declaração Universal dos Direitos Humanos ao tratar do direito à liberdade expressão e opinião enuncia que este "inclui a liberdade de, sem interferência, ter opiniões e de procurar, receber e transmitir informações e ideias por quaisquer meios e independentemente de fronteiras.” (ORGANIZAÇÃO DAS NAÇÕES UNIDAS, 1948). O artigo 19 do Pacto Internacional dos Direitos Civis e Políticos também trata do direito à liberdade de expressão e, igualmente, associa o referido direito à liberdade de "procurar, receber e difundir informações e idéias de qualquer natureza, independentemente de considerações de fronteiras, verbalmente ou por escrito, em forma impressa ou artística, ou por qualquer outro meio de sua escolha.” (ORGANIZAÇÃO DAS NAÇÕES UNIDAS, 1966).

Além dos tratados indicados acima firmados no âmbito da Organização das Nações Unidas há também importantes documentos no denominado Sistema Interamericano de Direitos Humanos. O artigo 13 da Convenção Americana de Direitos Humanos (Pacto de São José da Costa Rica) garante o direito à liberdade de expressão e assevera que este compreende a "liberdade de buscar, receber e difundir informações e idéias de toda natureza, sem consideração de fronteiras, verbalmente ou por escrito, ou em forma impressa ou artística, ou por qualquer outro processo de sua escolha.”

Revista Brasileira de Políticas Públicas e Internacionais, v. 5, n. 2, ago./2020, pp. 79-102. 
Simini \& Sala. Transparência e Acesso à Informação na Atuação Internacional do Município de São Paulo

(ORGANIZAÇÃO DOS ESTADOS AMERICANOS, 1969). Ademais, o mesmo artigo 13 da Convenção Americana de Direitos Humanos ressalta ser indevida qualquer restrição do direito de expressão por vias ou meios indiretos.

A Declaração de Princípios Sobre Liberdade de Expressão de 2000 considera ser a liberdade de expressão um direito fundamental, e não uma concessão do Estado, bem como assevera ser o direito um requisito indispensável para a própria existência de uma sociedade democrática. Igualmente, relaciona a liberdade de expressão com o direito de todo ser humano de receber, buscar e divulgar informações, com igualdade de oportunidades e sem qualquer discriminação. Além disso, observa que "o acesso à informação em poder do Estado é um direito fundamental do indivíduo. Os Estados estão obrigados a garantir o exercício desse direito.” (ORGANIZAÇÃO DOS ESTADOS AMERICANOS, 2000). A Carta Democrática Interamericana de 2001, por sua vez, reconhece que os povos da América têm direito à democracia, sendo o respeito ao direito de liberdade de expressão e a transparência das atividades governamentais componentes fundamentais do exercício da democracia.

O artigo 37, “caput”, da Constituição Federal de 1988 apresenta os denominados princípios constitucionais da administração pública, entre eles, o da publicidade. A mesma Constituição Federal enuncia em seu artigo $5^{\circ}$, XIV, ser assegurado a todos o acesso à informação e resguardado o sigilo da fonte, quando necessário ao exercício profissional. $\mathrm{O}$ artigo $5^{\circ}$, inciso XXXIII, enuncia que todos têm direito a receber dos órgãos públicos informações de seu interesse particular, ou de interesse coletivo ou geral, que serão prestadas no prazo da lei, sob pena de responsabilidade, ressalvadas aquelas cujo sigilo seja imprescindível à segurança da sociedade e do Estado.

A Constituição Federal de 1988 aponta ser a transparência administrativa a regra e o sigilo a exceção. Por isso, somente em situações excepcionais previstas no ordenamento jurídico pode haver restrição da transparência administrativa. A mesma Constituição Federal também assegura a todos o direito de acesso à informação, bem como garante o direito de petição para garantir o recebimento de informações de interesse particular ou público, também ressalvados os casos de sigilo quando as informações estiverem relacionadas à segurança da sociedade e do Estado.

Posteriormente, no ano de 2011, foi promulgada a Lei ${ }^{0} 12.527$, conhecida como “Lei do Acesso à Informação”. Este diploma normativo dispõe sobre os procedimentos a serem observados pela União, Estados, Distrito Federal, Municípios, com o fim de 
Simini \& Sala. Transparência e Acesso à Informação na Atuação Internacional do Município de São Paulo

garantir o acesso a informações previsto na própria Constituição Federal de 1988. De acordo com o artigo $6^{\circ}$ da Lei 12.527/11 cabe aos órgãos e entidades do poder público assegurar a gestão transparente da informação, propiciando amplo acesso a ela e sua divulgação, proteção da informação, garantindo-se sua disponibilidade, autenticidade e integridade, bem como proteção da informação sigilosa e da informação pessoal, observada a sua disponibilidade, autenticidade, integridade e eventual restrição de acesso.

O artigo $7^{\circ}$ da Lei 12.527/11 enuncia que o acesso à informação compreende, entre outros, os direitos de obter informação sobre atividades exercidas pelos órgãos e entidades, inclusive as relativas à sua política, organização e serviços, informação pertinente à administração do patrimônio público, utilização de recursos públicos, licitação, contratos administrativos, informação relativa à implementação, acompanhamento e resultados dos programas, projetos e ações dos órgãos e entidades públicas, metas e indicadores propostos, bem como informação relativa ao resultado de inspeções, auditorias, prestações e tomadas de contas realizadas pelos órgãos de controle interno e externo, incluindo prestações de contas relativas a exercícios anteriores.

Por outro lado, o artigo 10 da Lei 12.527/11 estabelece que qualquer interessado poderá apresentar pedido de acesso a informações aos órgãos e entidades referidos no art. $1^{0}$ desta Lei, por qualquer meio legítimo, devendo o pedido conter a identificação do requerente e a especificação da informação requerida. Ademais, também de acordo com o mesmo dispositivo legal, os órgãos e entidades do poder público devem viabilizar alternativa de encaminhamento de pedidos de acesso por meio de seus sítios oficiais na internet.

O Decreto Municipal 53.623/2012 de São Paulo regulamenta a Lei Federal $n^{\circ}$ 12.527/2011 no âmbito do Poder Executivo, estabelecendo procedimentos e outras providências correlatas para garantir o direito de acesso à informação. $\mathrm{O}$ artigo $2^{\circ}$ do referido Decreto estabelece que os órgãos e entidades municipais assegurarão, às “pessoas naturais e jurídicas, o direito de acesso à informação, mediante a adoção de procedimentos objetivos e ágeis, de forma transparente, clara e em linguagem de fácil compreensão, observados os princípios que regem a Administração Pública.” (SÃO PAULO, 2012). As regras e procedimentos previstos no Decreto 53.623/2012 são aplicáveis aos órgãos da administração direta, autarquias, fundações públicas, empresas públicas, as sociedades de economia mista e as demais entidades controladas direta ou indiretamente pelo município de São Paulo.

Revista Brasileira de Políticas Públicas e Internacionais, v. 5, n. 2, ago./2020, pp. 79-102. 
Simini \& Sala. Transparência e Acesso à Informação na Atuação Internacional do Município de São Paulo

A transparência tratada no Decreto 53.623/2012 é dividida em transparência ativa e transparência passiva. No que diz respeito à primeira espécie de transparência, o artigo 10 enuncia ser “dever dos órgãos e entidades da Administração Pública Municipal promover, independentemente de requerimento, a divulgação, na Internet, de informações de interesse coletivo ou geral por eles produzidas ou custodiadas.” (SÃO PAULO, 2012). As informações a serem divulgadas no Portal da Transparência do município de São Paulo, nos termos do artigo 10, parágrafo $1^{\text {0 }}$, do Decreto 53.623/2012 são os repasses ou transferências de recursos financeiros, execução orçamentária e financeira detalhada, licitações realizadas e em andamento, com editais, anexos e resultados, contratos firmados na íntegra, íntegra dos convênios firmados, bem como remuneração e subsídios recebidos por ocupantes de cargos, empregos ou funções públicas, incluídos eventuais auxílios, ajudas de custo, jetons e quaisquer outras vantagens pecuniárias, além dos proventos de aposentadoria e pensões, de forma individualizada, conforme ato da Secretaria Municipal de Planejamento, Orçamento e Gestão.

Ademais, também no que diz respeito à transparência ativa, o artigo 10, parágrafo $3^{\text {o }}$, do Decreto 53.623/2012 estabelece informações a serem divulgadas pelos órgãos municipais em seus respectivos sítios nas internet, quais sejam, estrutura organizacional, competências, legislação aplicável, principais cargos e seus ocupantes, endereço e telefones das unidades, horários de atendimento ao público; dados gerais para o acompanhamento de programas, ações, projetos e obras de órgãos e entidades; respostas a perguntas mais frequentes da sociedade; resultados de inspeções, auditorias, prestações e tomadas de contas realizadas pelos órgãos de controle interno, incluindo prestações de contas relativas a exercícios anteriores; contato da autoridade de monitoramento, bem como o telefone e o correio eletrônico do Serviço de Informações ao Cidadão - SIC do órgão ou entidade municipal.

O Capítulo IV do Decreto 53.623/2012 trata da transparência passiva, especialmente, o denominado "Serviço de Informação ao Cidadão". O artigo 12 determina que todos os órgãos da administração municipal direta ou indireta deverão dispor de, no mínimo, uma unidade física para atendimento ao público, com a finalidade de abrigar seu próprio "Serviços de Informação ao Cidadão”, o qual terá como objetivos receber e registrar pedidos de acesso à informação, além de atender, informar e orientar o público quanto ao acesso à informação. As competências do "Serviço de Informação ao Cidadão" são o recebimento do pedido de acesso e, sempre que possível, o fornecimento

Revista Brasileira de Políticas Públicas e Internacionais, v. 5, n. 2, ago./2020, pp. 79-102. 
Simini \& Sala. Transparência e Acesso à Informação na Atuação Internacional do Município de São Paulo

imediato da informação; o registro do pedido de acesso em sistema eletrônico específico e a entrega do número de protocolo, que conterá a data de apresentação do pedido; o encaminhamento do pedido recebido e registrado ao responsável pelo fornecimento da informação. O pedido de acesso à informação poderá ser formulado de forma presencial ou através de meio eletrônico por qualquer pessoa física ou jurídica devidamente identificada.

\section{Transparência e Acesso à Informação na Atuação Internacional do Município de São Paulo}

A Prefeitura de São Paulo disponibiliza na internet (SÃO PAULO, [2020d]) no denominado "Portal da Transparência", relatórios anuais contendo estatísticas referentes ao "Serviço de Informação ao Cidadão". Atualmente estão disponíveis sete relatórios referentes aos anos de 2012/2013 (maio de 2012 a abril de 2013), 2013/2014 (maio de 2013 a abril de 2014), 2014/2015 (maio de 2014 a abril de 2015), 2015/2016 (maio de 2015 a abril de 2016), 2016 (janeiro a dezembro de 2016), 2017 (janeiro a dezembro de 2017) e 2018 (janeiro a dezembro de 2018). Nos relatórios disponíveis a pasta responsável pela atuação internacional de São Paulo ainda era denominada Secretaria Municipal de Relações Internacionais.

No ano de 2012 foram apresentadas 295 solicitações de informações, sendo 245 delas atendidas pela municipalidade. Do total de 295 solicitações, apenas 1 (uma) foi direcionada à Secretaria Municipal de Relações Internacionais, correspondente a 0,33\% do total de pedidos recebidos. A Secretaria Municipal de Saúde foi a pasta que recebeu mais solicitações naquele ano, totalizando 23 pedidos de informação, seguida pela Secretaria Municipal de Finanças e Desenvolvimento Econômico (22 pedidos), Secretaria Municipal de Planejamento, Orçamento e Gestão (19 pedidos), Companhia de Engenharia de Tráfego (13 pedidos) e Secretaria Municipal de Assistência de Desenvolvimento Social (13 pedidos).

De acordo com o segundo relatório, de maio de 2013 a abril de 2014, foram registrados 2.852 protocolos no "Sistema de Informação ao Cidadão", um aumento de 142\% em relação ao período anterior. Do total de solicitações, 77\% foram atendidas. A Companhia de Engenharia de Tráfego foi o órgão que mais recebeu informações (237 solicitações), seguido pela Secretaria Municipal de Finanças e Desenvolvimento Econômico (224 solicitações) e São Paulo Transportes (188 solicitações). A Secretaria

Revista Brasileira de Políticas Públicas e Internacionais, v. 5, n. 2, ago./2020, pp. 79-102. 
Simini \& Sala. Transparência e Acesso à Informação na Atuação Internacional do Município de São Paulo

Municipal de Relações Internacionais e Federativas recebeu apenas 04 solicitações de informações, correspondente a $0,14 \%$ do total de pedidos recebidos, figurando nas últimas posições. Entre abril de 2013 (primeiro relatório) e maio de 2014 (segundo relatório) houve um acréscimo de 300\% no número de pedidos de acesso à informação destinados à Secretaria Municipal de Relações Internacionais.

O terceiro relatório referente aos anos de 2014/2015 indica que entre $1^{\circ}$ de maio de 2014 a 30 de abril de 2015 foram registrados 2.912 solicitações de informação. De acordo com o próprio relatório cinco unidades respondem por mais de um terço (36\%) das solicitações: Companhia de Engenharia de Tráfego (294 solicitações), Secretaria Municipal de Educação (223 solicitações), Secretaria Municipal de Saúde (194 solicitações), Secretaria Municipal de Finanças e Desenvolvimento Econômico (185 solicitações) e São Paulo Transportes (155 solicitações). A Secretaria Municipal de Relações Internacionais de São Paulo recebeu apenas 03 (três) solicitações de informações, correspondente a $0,1 \%$ do total de pedidos recebidos, figurando novamente nas últimas posições. Ademais, deve-se observar que entre maio de 2014 (segundo relatório) e abril de 2015 (terceiro relatório) houve um decréscimo de 25\% no total de pedidos endereçados à Secretaria Municipal de Relações Internacionais.

O quarto relatório disponível indica que entre 01 de maio de 2015 e 30 de abril de 2016 foram registrados 4.565 solicitações de informações, um aumento de 57\% em relação ao período anterior. Novamente a Companhia de Engenharia de Tráfego aparece em primeiro lugar com 536 solicitações de informações, seguida pela Secretaria Municipal de Saúde com 393 solicitações, Secretaria Municipal de Educação com 305 solicitações, São Paulo Transportes com 282 solicitações e Secretaria Municipal de Finanças e Desenvolvimento Econômico com 265 solicitações. Estes cinco órgãos, da mesma forma que ocorreu no relatório anterior, respondem por mais de um terço (39\%) das solicitações. A Secretaria Municipal de Relações Internacionais nesse mesmo período recebeu apenas 05 (cinco) solicitações de informações, correspondente a 0,11\% do total de pedidos recebidos, figurando mais uma vez nas últimas posições. Entre abril de 2015 (terceiro relatório) e abril de 2016 (quarto relatório) houve um acréscimo de 66\% no número de pedidos de informação endereçados à Secretaria Municipal de Relações Internacionais.

O quinto relatório disponível referente ao ano de 2016 (janeiro a dezembro) indica um total de 5.212 solicitações de acesso à informação, uma média de 434,3 pedidos por

Revista Brasileira de Políticas Públicas e Internacionais, v. 5, n. 2, ago./2020, pp. 79-102. 
Simini \& Sala. Transparência e Acesso à Informação na Atuação Internacional do Município de São Paulo

mês. De acordo com o próprio relatório, houve em termos gerais um acréscimo na média mensal de pedidos, pois em 2012 registrou-se 73,8 pedidos por mês, em 2013 foram registrados 210,1 pedidos por mês, no ano de 2014 foram registrados 200,3 pedidos por mês e no ano de 2015 foram registrados 351,4 pedidos por mês. Os órgãos que mais receberam pedidos de acesso à informação foram a Companhia de Engenharia de Tráfego (459 pedidos), a Secretaria Municipal de Educação (383 pedidos), a Secretaria Municipal da Saúde (373 pedidos), a Secretaria Municipal da Fazenda (318 pedidos) e a Secretaria Municipal de Mobilidade e Transportes (303 pedidos). Estes cinco órgãos receberam juntos o correspondente a 35\% da solicitações de acesso à informação. A Secretaria Municipal de Relações Internacionais recebeu entre janeiro a dezembro de 2016 apenas 06 (seis) solicitações de acesso à informação, correspondente a 0,12\% do total de pedidos recebidos, figurando na penúltima posição, ficando na frente apenas da Secretaria Municipal de Urbanismo e Licenciamento.

O sexto relatório disponível referente ao ano de 2017 (janeiro a dezembro) indica que foram recebidos 7.860 pedidos de acesso à informação, ou seja, constata-se entre os anos de 2014 e 2017 houve um acréscimo de mais de 225\% no número de pedidos, pois no ano de 2014 foram registrados 2.404 solicitações e no ano de 2017 um total de 7.860 pedidos de acesso à informação. No ano de 2017 verifica-se, portanto, uma média de 655 pedidos de acesso à informação por mês. No referido ano a Secretaria Municipal de Saúde (738 pedidos), a Secretaria Municipal de Educação (649 pedidos), a Companhia de Engenharia de Tráfego (553 pedidos), a São Paulo Transportes S/A (427 pedidos) e a Secretaria Municipal de Transportes e Mobilidade (382 pedidos) figuraram nas cinco primeiras posições, sendo responsáveis pelo recebimento de 34,9\% dos pedidos de acesso à informação. A Secretaria Municipal de Relações Internacionais recebeu um total de 21 (vinte e um) pedidos de acesso à informação no ano de 2017, um acréscimo de 250\% em relação ao ano de 2016. Porém, apesar do acréscimo em relação ao ano anterior, os pedidos de acesso à informação recebidos pela Secretaria Municipal de Relações Internacionais corresponderam a 0,27\% do total de pedidos registrados no ano de 2017.

O sétimo e último relatório disponível referente ao ano de 2018 (janeiro a dezembro) indica um total de 8.103 pedidos de acesso à informação, uma média de 675,25 pedidos por mês, um acréscimo de 3,09\% em relação ao ano de 2017. A Secretaria Municipal de Educação figura em primeiro lugar com 623 pedidos, seguida pela Secretaria Municipal da Saúde com 605 pedidos, Secretaria Municipal de Mobilidade e

Revista Brasileira de Políticas Públicas e Internacionais, v. 5, n. 2, ago./2020, pp. 79-102. 
Simini \& Sala. Transparência e Acesso à Informação na Atuação Internacional do Município de São Paulo

Transportes com 570 pedidos, São Paulo Transportes S/A com 496 pedidos e a Companhia de Engenharia de Tráfego com 473 pedidos. Estes cinco órgãos receberam juntos o correspondente a 34\% do total de pedidos de acesso à informação em 2018. A Secretaria Municipal de Relações Internacionais, por sua vez, recebeu 11 (onze) pedidos de acesso à informação no ano de 2018, correspondente a 0,14\% do total de pedidos recebidos no referido ano, um decréscimo correspondente 47,61\% se comparado com o ano de 2017.

No gráfico abaixo a oscilação no número de pedidos de acesso à informação destinados à Secretaria Municipal de Relações Internacionais de São Paulo:

Figura 01: Pedidos de informações - SMRI/SP

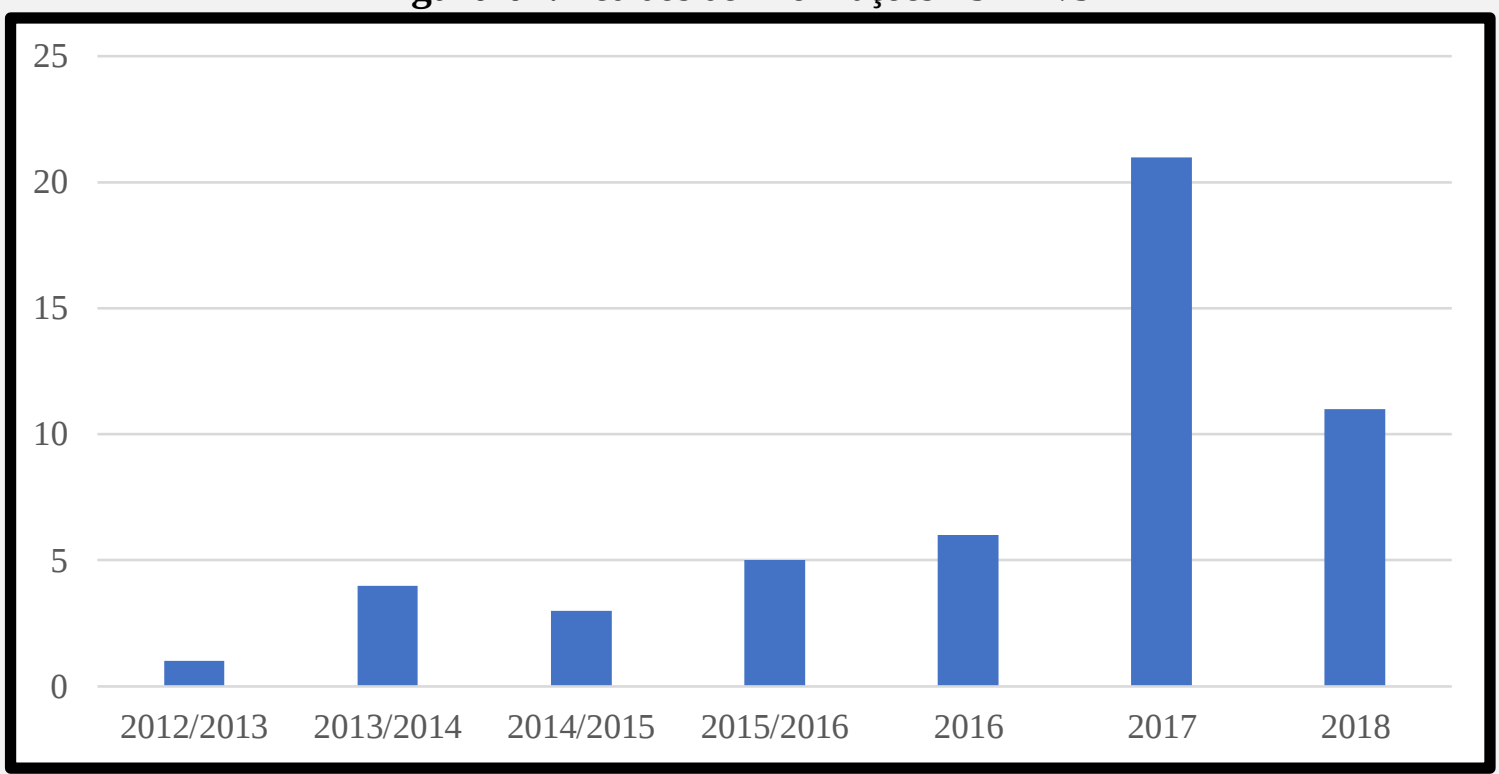

Fonte: Elaboração própria.

Comparando-se o número total de pedidos, constata-se que entre 2012 (295 pedidos) e 2018 (8.103 pedidos) houve um acréscimo de 2.646\%. Contudo, o mesmo aumento relevante não se constata quando analisa-se apenas o número de pedidos de acesso à informação destinados à Secretaria Municipal de Relações Internacionais, pois esta pasta teve oscilações nos números de pedidos de acesso à informação nos anos analisados, havendo acréscimos e decréscimos de um ano para outro. Ademais, a pasta sempre esteve nas últimas posições no ranking de órgãos municipais com maior número de pedidos, bem como a Secretaria Municipal de Relações Internacionais nunca ultrapassou o correspondente a $0,1 \%$ do total de pedidos recebidos pelo município.

Revista Brasileira de Políticas Públicas e Internacionais, v. 5, n. 2, ago./2020, pp. 79-102. 
Simini \& Sala. Transparência e Acesso à Informação na Atuação Internacional do Município de São Paulo

O gráfico abaixo compara o número total de pedidos e o número de pedidos endereçados à Secretaria Municipal de Relações Internacionais em cada relatório disponibilizado pelo Portal da Transparência.

Figura 02: Pedidos de Acesso à Informação

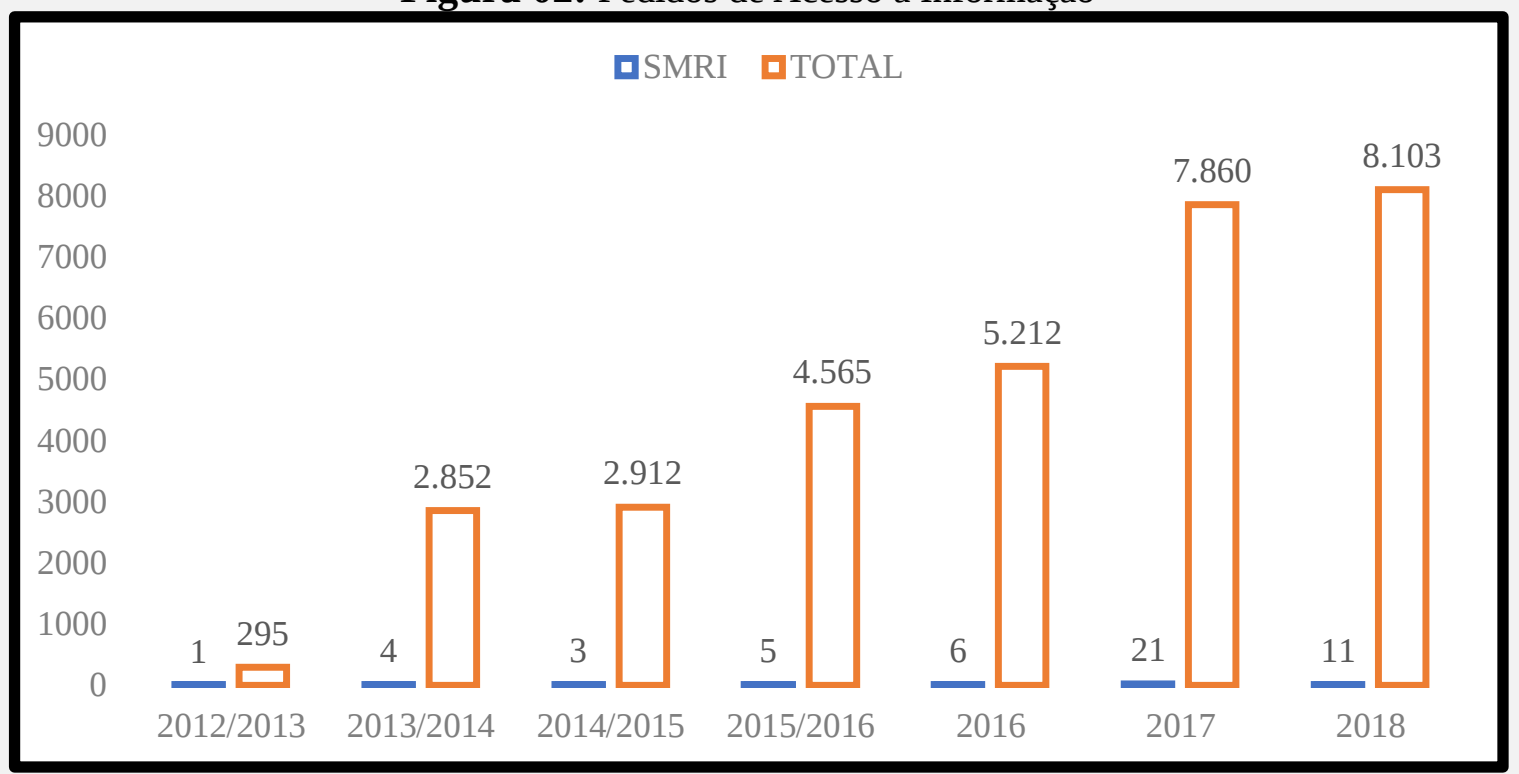

Fonte: Elaboração própria

Através das informações coletadas constata-se um crescimento considerável no número de pedidos de informação junto ao "Sistema de Informação ao Cidadão" da Prefeitura de São Paulo. Porém, historicamente, praticamente os mesmos órgãos respondem por mais de um terço dos pedidos, sendo que em todos os relatórios a Secretaria Municipal de Relações Internacionais figura nas últimas posições, recebendo pouquíssimos pedidos dos cidadãos. Os poucos pedidos existentes direcionados à Secretaria visam amparar pesquisas acadêmicas ou tratam de informações sobre gastos da pasta, número de funcionários e contratos celebrados, etc, conforme informações disponibilizadas pelo site da Prefeitura de São Paulo.

Não obstante ser um número ainda pequeno de pedidos de acesso à informação, em algumas oportunidades, o "Serviço de Informação ao Cidadão" foi utilizado como ferramenta de fiscalização e controle da atuação internacional do município de São Paulo, pois, em mais de uma oportunidade, foram solicitadas informações relacionadas aos contratos celebrados, licitações realizadas, número de funcionários, gastos com viagens, etc. Trata-se de uma fiscalização pequena, porém já existente por parte da sociedade, ao contrário, por exemplo, do Poder Legislativo municipal. Este sem qualquer atividade fiscalizatória, não obstante a existência de uma Comissão de Relações Internacionais na

Revista Brasileira de Políticas Públicas e Internacionais, v. 5, n. 2, ago./2020, pp. 79-102. 
Simini \& Sala. Transparência e Acesso à Informação na Atuação Internacional do Município de São Paulo

Câmara de Vereadores, cuja função é justamente fiscalizar e acompanhar a atuação internacional do município de São Paulo (SIMINI, 2017).

A demanda por informação por parte da sociedade civil faz com que a atuação internacional de municípios enquanto política pública seja mais democrática e participativa, conforme dito anteriormente. Mecanismos de acesso à informação já existem a fim de efetivar-se a transparência administrativa. $O$ desafio é tornar a atuação internacional dos municípios mais conhecida por parte da sociedade civil a fim de que esta a entenda como uma verdadeira política pública apta a trazer benefícios para a população em geral.

Nas circunstâncias que estamos vivendo atualmente -o presente artigo foi enviado no início do quinto mês da pandemia Covid 19 no Brasil- encontramos uma prova mais do que evidente sobre a importância da atuação internacional dos municípios, mormente aqueles populosos como São Paulo.

Assim como o governo do estado, o município de São Paulo tem promovido reuniões, em salas virtuais, com representantes diplomáticos e comerciais de diversos países, com vistas à troca de informações, conhecimento e tecnologia sobre a pandemia e como resolver os problemas dela decorrentes - sejam sanitários, humanos e econômicos.

Recentemente, por exemplo, em 29 de junho do corrente ano, com o objetivo de dialogar sobre medidas de combate ao Covid 19 e proteção à população, a reabertura das cidades e os cenários futuros pós-pandemia, as prefeituras de São Paulo e de Milão, na Itália, participaram de uma videoconferência. A reunião virtual ocorreu no contexto do Programa Internacional de Cooperação Urbana (IUC), da União Europeia.

Durante a reunião, os participantes conversaram sobre a importância da comunicação com os cidadãos em relação à covid-19 e sobre o processo de retomada das atividades econômicas. Outro ponto da videoconferência consistiu na apresentação do mapeamento das experiências internacionais no combate à pandemia.

São Paulo e Milão são cidades-irmã desde 1962. Em 2015, a cidade de São Paulo se tornou signatária do Pacto de Milão sobre Políticas de Alimentação Urbana, um documento assinado por 145 prefeitos do mundo para reconhecer o papel estratégico das cidades no desenvolvimento de sistemas alimentares sustentáveis e no combate à insegurança alimentar.

Revista Brasileira de Políticas Públicas e Internacionais, v. 5, n. 2, ago./2020, pp. 79-102. 
Simini \& Sala. Transparência e Acesso à Informação na Atuação Internacional do Município de São Paulo

Além dessa parceria, como já mencionado, as cidades atuam juntas no Programa Internacional de Cooperação Urbana (IUC) no tema “requalificação de espaços urbanos públicos”. O IUC busca realizar a conexão entre as cidades de diferentes regiões do mundo para promover o desenvolvimento urbano sustentável em cooperação com os setores públicos e privados e com grupos e cidadãos da comunidade. Os países em foco desta iniciativa são China, Índia, Japão, Canadá, México, Estados Unidos, Argentina, Brasil, Chile, Colômbia e Peru (SÃO PAULO, 2020e).

De forma geral, graças às boas relações advindas da estreita colaboração internacional foi possível centenas de doações já recebidas em São Paulo, de máscaras cirúrgicas, EPIs, monitores de sinais vitais, desfibriladores, ventiladores pulmonares, luvas e demais instrumentos e materiais de proteção para nossos agentes de saúde.

Como afirmam Buss e Tobar (2020) em artigo recente sobre cooperação internacional na área da saúde, a estruturação formal e institucional dessas relações intergovernamentais ao mais alto nível abrirá o caminho e incentivará a cooperação vital entre universidades, institutos de pesquisa, escolas de saúde pública e escolas de graduação nas áreas da saúde, promovendo o estabelecimento de projetos de treinamento e pesquisa de recursos humanos e desenvolvimento tecnológico que responda às necessidades comuns dos países de nossa região no enfrentamento da epidemia.

Essa cooperação na sub-região reforçaria a ação continental da OPAS, que reúne todos os países das Américas, nesta importante iniciativa no campo da diplomacia regional da saúde.

Some-se à referida ação internacional a necessidade de promover a transparência e o acesso à informação a fim de evitar situações constrangedoras de corrupção como as que temos vivenciado justamente neste período de pandemia, onde é preciso fiscalizar a atuação de agentes governamentais também nos acordos e transações com entes estrangeiros a fim de evitar o que, a título de exemplo, aconteceu recentemente no Rio de Janeiro, ao realizar compras fraudulentas de material hospitalar.

\section{Considerações Finais}

Entender a atuação internacional dos municípios no Brasil como política pública traz questionamentos e desafios. Políticas públicas exigem transparência e acesso à informação. Assim, a sociedade civil munida de informações poderá participar das políticas públicas e também fiscalizá-las. A transparência administrativa e o acesso à 
Simini \& Sala. Transparência e Acesso à Informação na Atuação Internacional do Município de São Paulo

informação são, portanto, condições fundamentais para o exercício efetivo da democracia e da cidadania. Logo, reflexões também devem ser feitas acerca da transparência e do acesso à informação no que se refere à atuação internacional dos municípios no Brasil. Trazer tais questionamentos e reflexões foi o principal objetivo do presente artigo.

O município de São Paulo em razão do seu pioneirismo foi o escolhido como objeto de análise. Os documentos disponíveis pela própria municipalidade demonstram um crescimento significativo em termos de pedidos de acesso à informação, demonstrando, ao menos teoricamente, um maior interesse da população em relação às políticas públicas municipais. Contudo, o número de pedidos de acesso à informação destinados à Secretaria Municipal de Relações Internacionais ainda se mostra pequeno se comparado com o total de pedidos.

A existência de uma pequena procura por informações acerca da atuação internacional do município de São Paulo pode ter várias possíveis explicações. A sociedade civil talvez não conheça ainda o trabalho desenvolvido pela Secretaria Municipal de Relações Internacionais ou conhecendo acredita ser a atuação internacional uma política pública sem relação com o cotidiano do cidadão em uma cidade do porte de São Paulo.

$\mathrm{Na}$ verdade, na data de hoje, enquanto concluímos este artigo, em pleno desenvolvimento da pandemia do Covid-19, o paulistano começou a perceber a relevância da ação internacional especialmente em momentos de crise, sendo o município de São Paulo um exemplo de coordenação com ONGs, empresas multinacionais e organizações intergovernamentais a fim otimizar a cooperação para o combate do vírus e os seus efeitos na economia.

De qualquer forma, os poucos pedidos de acesso à informação durante o período analisado demonstram um potencial, pois os requerimentos solicitando informações referentes aos contratos celebrados, número de funcionários, gastos, entre outras, indicam a existência de uma atividade fiscalizatória por parte da sociedade civil, mesmo que ínfima e incipiente, sendo justamente a possibilidade de uma maior fiscalização da atividade pública um dos objetivos da descentralização política e valorização do poder local no Brasil.

Poderíamos arriscar, inclusive, a conclusão de que é no âmbito local da atuação internacional onde, como verdadeira política pública, a transparência e o acesso à 
Simini \& Sala. Transparência e Acesso à Informação na Atuação Internacional do Município de São Paulo

informação é mais próximo, veraz e significativo. Prenuncio de uma progressiva ampliação para outros âmbitos federativos.

\section{Referências}

Araújo, Izabela Viana de (2012). A influência partidária no nível municipal: paradiplomacia na cidade de São Paulo. 2012. Dissertação (Mestrado em Relações Internacionais) - Instituto de Relações Internacionais, Universidade de São Paulo, São Paulo.

Blanes Sala, José \& Carvalho, Fagner dos Santos (2013). A autonomia municipal no Brasil e sua recente ação internacional. In: Marchetti, Vitor. (Org.). Políticas públicas em debate. São Bernardo do Campo: MP Editora, v. 1, p. 231-250.

Blanes Sala, José \& Santos, Clara Maria Faria (2009). O fundamento jurídico para a ação internacional do Município de São Paulo. In: BLANES SALA, José (Org.). O município e as relações internacionais: aspectos jurídicos. São Paulo: Educ.

BRASIL (1988). Constituição da República Federativa, de 5 de outubro de 1988. Recuperado de: www.planalto.gov.br/ccivil_03/Constituicao/Constitui\%C3\%A7ao.htm. Acesso em: 21 de abr. 2020.

BRASIL (2011). Lei 12.527 de 18 de novembro de 2011. Regula o acesso a informações previsto no inciso XXXIII do art. $5^{\circ}$, no inciso II do $\S 3^{\circ}$ do art. 37 e no $\S 2^{\circ}$ do art. 216 da Constituição Federal; altera a Lei ${ }^{\circ}$ 8.112, de 11 de dezembro de 1990; revoga a Lei $\mathrm{n}^{0}$ 11.111, de 5 de maio de 2005, e dispositivos da Lei $\mathrm{n}^{\circ}$ 8.159, de 8 de janeiro de 1991; e dá outras providências. Disponível em: $<$ http://www.planalto.gov.br/ccivil_03/_ato2011-2014/2011/lei/12527.htm>. Acesso em: 21 de abr. 2020.

Brigagão, Clóvis (2005). Relações Internacionais Federativas no Brasil: Estados e Municípios. Rio de Janeiro: Gramma.

Buss, Paulo Marchiori; Tobar, Sebástian. COVID-19 and opportunities for international cooperation in health. Cadernos de Saúde Pública, vol. 36, n. 4, 2020.

CONFEDERAÇÃO NACIONAL DE MUNICÍPIOS (2011). Atuação global municipal: dimensões e institucionalização. Brasília, DF.

Fonseca, Marcela Garcia (2013). Os entes federativos brasileiros frente ao direito internacional. 2013. Tese (Doutorado em Relações Internacionais) - Instituto de Relações Internacionais, Universidade de São Paulo, São Paulo.

Fronzaglia, Maurício Loboda (2005). Unidades subnacionais: um estudo de caso sobre a cidade de São Paulo - de 2001 a 2004. Dissertação (Mestrado em Ciência Política) Instituto de Filosofia e Ciências Humanas, Universidade Estadual de Campinas, Campinas. 
Simini \& Sala. Transparência e Acesso à Informação na Atuação Internacional do Município de São Paulo

Junqueira, Cairo Gabriel Borges (2015). A criação das Secretarias Municipais de Relações Internacionais (SMRIs) como nova realidade da inserção internacional dos entes subnacionais brasileiro. Boletim de Economia e Política Internacional, n. 21, set/dez.

LAISNER, Regina (2013). O empoderamento dos governos locais e a constituição das Secretarias Municipais de Relações Internacionais (SMRI): um mapeamento no Brasil. Relatório Final. Projeto Conselho Nacional de Desenvolvimento Científico e Tecnológico.

Melo, Marcus André (1999). Crise federativa, guerra fiscal e hobbesianismo municipal: efeitos perversos da descentralização? In: OLIVEIRA, M.A. (Org.). Politica e contemporaneidade no Brasil. Recife: Edições Bagaço.

Mercher, Leonardo \& Pereira, Alexsandro Eugenio (2018). Paradiplomacia como política externa e política pública: modelo de análise aplicado ao caso da cidade do Rio de Janeiro. Revista Carta Internacional, v. 13, n. 2, p. 195-222.

Mohn, Paulo Fernando (2006). Autonomia municipal, centralização e liberdade. Revista de

Informação Legislativa, Brasília, nº 171, p. 199-209, jul/set.

ORGANIZAÇÃO DAS NAÇÕES UNIDAS (1948). Declaração Universal dos Direitos Humanos. Disponível em < https://nacoesunidas.org/wp-content/uploads/2018/10/ DUDH.pdf $>$ Acesso em 22. abr. 2020.

ORGANIZAÇÃO DAS NAÇÕES UNIDAS (1966). Pacto Internacional dos Direitos Civis e Políticos. Disponível em < http://www.planalto.gov.br/ccivil_03/decreto/19901994/d0592.htm> Acesso em 22. abr. 2020.

ORGANIZAÇÃO DOS ESTADOS AMERICANOS (1969). Convenção Americana de Direitos Humanos. Disponível em $<$ https://www.cidh.oas.org/basicos/portugues/c.convencao_americana.htm> Acesso em 22. abr. 2020.

ORGANIZAÇÃO DOS ESTADOS AMERICANOS (2000). Declaração de Princípios Sobre Liberdade de Expressão. Disponível em <https://www.cidh.oas.org/ basicos/portugues/s.Convencao.Libertade.de.Expressao.htm $>$ Acesso em 22 de abr. 2020.

ORGANIZAÇÃO DOS ESTADOS AMERICANOS (2001). Carta Democrática Interamericana. Disponível em < http://www.oas.org/OASpage/port/Documents/Democractic_Charter.htm> Acesso em 22 de abr. 2020.

Ratton Sanchez, Michelle; Silva, Elaine; Cardoso, Evorah; Specie, Priscila (2006). Política externa como política pública: uma análise pela regulamentação constitucional brasileira (1967-1988). Revista Sociologia Política, n. 27, p. 125-143, nov.

Revista Brasileira de Políticas Públicas e Internacionais, v. 5, n. 2, ago./2020, pp. 79-102. 
Simini \& Sala. Transparência e Acesso à Informação na Atuação Internacional do Município de São Paulo

Ribeiro, Maria Clotilde Meirelles (2009). Globalização e novos atores: a paradiplomacia das cidades brasileiras. Salvador: Universidade Federal da Bahia.

Romão, Wagner de Melo (2009). O novo contexto das relações internacionais e a ação externa das cidades brasileiras. In: Rodrigues, Gilberto Marcos Antônio; Xavier, Marcos; Romão, Wagner de Melo (Org.). Cidades em relações internacionais: análises e experiências brasileiras. São Paulo: Desatino.

Santos, Clara Maria Faria (2010). Capacidade jurídica internacional dos municípios. 2010. Dissertação (Mestrado em Ciências Sociais) - Faculdade de Ciências e Letras, Universidade Estadual Paulista Júlio de Mesquita Filho.

SÃO PAULO (MUNICÍPIO) (2001). Lei 13.165 de 05 de julho de 2001. Cria a Secretaria Municipal de Relações Internacionais - SMRI e dá outras providências. Disponível em $<$ http://camaramunicipalsp.qaplaweb.com.br/iah/fulltext/leis/L13165.pdf> Acesso em 03 de ago. de 2016.

SÃO PAULO (MUNICÍPIO) (2012). Decreto 53.623/2012. Regulamenta a Lei Federal $n^{\circ}$ 12.527, de 18 de novembro de 2011, no âmbito do Poder Executivo, estabelecendo procedimentos e outras providências correlatas para garantir o direito de acesso à informação, conforme especifica. Disponível em < http://legislacao.prefeitura.sp.gov.br/leis/decreto-53623-de-12-de-dezembro-de2012/detalhe> Acesso em 21 de 2020.

SÃO PAULO (MUNICÍPIO) (2013). Lei no 15.764 de 27 de maio de 2013. Dispõe sobre a criação e alteração da estrutura organizacional das Secretarias Municipais que especifica.Disponível<http://www3.prefeitura.sp.gov.br/cadlem/secretarias/negocios_jr idicos/cadlem/integra.asp?alt=28052013L\%20157640000> Acesso em 03 de ago. de 2016.

SÃO PAULO (MUNICÍPIO) Secretaria Municipal de Relações Internacionais e Federativas de São Paulo. Assuntos internacionais: acordos de cooperação bilateral. São Paulo, [2020a], Disponível em: <https://www.prefeitura.sp.gov.br/cidade/ secretarias/relacoes_internacionais/assuntos_internacionais/index.php?p=270291>.

Acesso em: 21 abr. 2020.

SÃO PAULO (MUNICÍPIO) Secretaria Municipal de Relações Internacionais e Federativas de São Paulo. Assuntos internacionais: acordos de cooperação multilateral. São Paulo, [2020b], Disponível em: < https://www.prefeitura.sp.gov.br/ cidade/secretarias/relacoes_internacionais/assuntos

internacionais/index.php?p=270126>. Acesso em: 21 abr. 2020.

SÃO PAULO (MUNICÍPIO) Secretaria Municipal de Relações Internacionais e Federativas de São Paulo. Assuntos internacionais: redes de cidades. São Paulo, [2020c], Disponível em: <https://www.prefeitura.sp.gov.br/cidade/secretarias/relacoes_ internacionais/assuntos_internacionais/index.php?p=146132>. Acesso em: 21 abr. 2020.

SÃO PAULO (MUNICÍPIO) Portal da Transparência. Relatórios Anuais da LAI. São Paulo, [2020d], Disponível em: < http://transparencia.prefeitura.sp.gov.br/acesso-a- 
Simini \& Sala. Transparência e Acesso à Informação na Atuação Internacional do Município de São Paulo

informacao/Paginas/Relat\%c3\%b3rios-Estat\%c3\%adsticos.aspx>. Acesso em: 21 abr. 2020.

SÃO PAULO (MUNICÍPIO) Capital participa de videoconferência sobre o enfrentamento à covid-19 com a cidade de Milão. São Paulo, [2020e], Disponível em: < http://www.capital.sp.gov.br/noticia/capital-participa-de-videoconferencia-sobre-oenfrentamento-a-covid-19-com-a-cidade-de-milao> Acesso em 03 ago. 2020.

Simini, Danilo Garnica (2015). Atuação internacional dos municípios brasileiros à luz da Constituição Dirigente de 1988: um estudo de caso da Secretaria Municipal de Relações Internacionais e Federativas de São Paulo.147 f. Dissertação (Mestrado)Programa de Pós-Graduação em Direito, Faculdade de Ciências Humanas e Sociais, Universidade Estadual Paulista “Júlio de Mesquita Filho”, Franca.

(2017). Accountability e atuação internacional do município de São Paulo. Monções: Revista de Relações Internacionais da UFGD, Dourados, v. 6, n. 12, jul./dez.

Simini, Danilo Garnica; Laisner, Regina Claudia (2018). Superação do subdesenvolvimento, erradicação da pobreza e atuação internacional de municípios: o exemplo da cidade de São Paulo. Revista de Direito da Cidade, Rio de Janeiro, volume 10, n. 1, p. 225-256.

Souza, Celina (2005). Federalismo, desenho constitucional e as instituições federativas no Brasil pós-1988. Revista Sociologia Política, Curitiba, n. 24, p. 105-121, jun.

(2006). Políticas públicas: uma revisão da literatura. Sociologias, Porto Alegre, ano 08, no 16, p. 20-45, jul/dez.

Vigevani, Tullo (2006). Problemas para a atividade internacional das unidades subnacionais: estados e municípios brasileiros. Revista Brasileira de Ciências Sociais, São Paulo, v. 21, n. 62, p. 127-169.

Vital, Graziela Cristina (2016). 232 f. A institucionalização das relações externas subnacionais: um estudo comparado das cidades de São Paulo e Toronto. Tese (Doutorado)-Programa de Pós-Graduação em Relações Internacionais, Instituto de Relações Internacionais, Universidade de São Paulo, São Paulo.

Revista Brasileira de Políticas Públicas e Internacionais, v. 5, n. 2, ago./2020, pp. 79-102. 